\title{
Persepsi Wisatawan Terhadap Wisata Pedestrian Sudirman Sebagai Tujuan Wisata Malam Kota Palembang
}

\author{
Muhammad Subakti, Yasir Arafat, Budi Utomo
}

Masuk: 12122019 / Diterima: 30122020 / Dipublikasi: 30062021

\begin{abstract}
Sudirman Pedestrian is used as a night tour that can attract the public's attention for night trips in the city of Palembang. The purpose of this study was to explore people's perceptions of Sudirman Pedestrian Tourism. The research method used is a qualitative descriptive approach. The data source of this research is ten tourists in Sudirman Pedestrian Tour Palembang City by snowball sampling. Data analysis techniques in this study used data reduction, data presentation, and concluding. The results showed that the perception of tourists about Sudirman pedestrian tourism was in a suitable category. Tourists feel safe and comfortable when on the Sudirman Pedestrian Tour, even at night. This is due to the beautiful panorama and exciting and unique attraction performances for visitors. Based on these findings, Sudirman Pedestrian Tourism can be developed as the leading destination for night tours in Palembang City by increasing utility and increasing space for tourist attractions from the local community.
\end{abstract}

Key words: Tourist Perceptions; Night tour; Sudirman Pedestrian Tour

\begin{abstract}
Abstrak Pedestrian Sudirman dijadikan sebagai wisata malam yang mampu menarik perhatian masyarakat untuk berwisata malam di Kota Palembang. Tujuan penelitian ini untuk mengeksplorasi persepsi masyarakat terhadap Wisata Pedestrian Sudirman. Metode penelitian yang digunakan adalah pendekatan deskriptif kualitatif. Sumber data penelitian ini adalah wisatawan yang ada di Wisata Pedestrian Sudirman Kota Palembang yang berjumlah 10 orang secara snowball sampling. Teknik analisis data dalam penelitian ini menggunakan reduksi data, penyajian data, dan penarikan kesimpulan. Hasil penelitian memperlihatkan bahwa persepsi wisatawan mengenai wisata pedestrian sudirman dalam kategori baik. Wisatawan merasa aman dan nyaman ketika berada di Wisata Pedestrian Sudirman meskipun di malam hari. Hal ini disebabkan panorama yang indah serta pertunjukan atraksi yang menarik dan unik bagi para pengunjung. Berdasarkan temuan tersebut, Wisata Pedestrian Sudirman dapat dikembangkan sebagai tujuan utama wisata malam di Kota Palembang dengan meningkatkan utilitas dan menambah ruang untuk atraksi wisata dari masyarakat lokal.
\end{abstract}

Kata kunci: Persepsi Wisatawan; Wisata Malam; Wisata Pedestrian Sudirman

This is an open access article under the CC BY-SA license.

Copyright $\odot 2021$ by Author. Published by Universitas Pendidikan Ganesha.

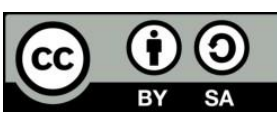

\section{Pendahuluan}

Kawasan sudirman merupakan salah satu pusat pertumbuhan di Kota Palembang sebagai jantung pusat Kota

Muhammad Subakti, Yasir Arafat, Budi Utomo Universitas PGRI Palembang, Indonesia
Palembang. Di kawasasan ini dikiri kanan jalan dibangun pedestrian. Fungsi utama jalur pedestrian adalah sebagai jalur pejalan kaki yang nyaman dan aman (Mauliani, 2010; Muslihun, 2013; Oswan \& Sigit, 2013). Namun 
keberadaan pedestrian sudirman ketika malam hari dijadikan wisata malam.

Pemanfaatan wisata pedestrian sudirman atas dasar potensi yang dimiliki untuk dikembangkan menjadi destinasi baru (Ditarani \& Wibisono, 2020). Pengembangan menjadi wisata pedestrian dengan melakukan pelebaran pedestrian, penambahan fasilitas kursi, pot taman, lampu taman, tempat sampah, area parkir dan penyelenggaraan acara pada akhir pekan sebagai daya tarik wisata.

Sebagai tempat wisata menarik wisatawan berkunjung baik dari dalam maupun luar Kota Palembang. Pedestrian sudirman semakin berkembang dengan berbagai kegiatan aktivitas ekonomi (Pedagang Kaki Lima (PKL)), dan sosial (Pratitis, 2015). Banyaknya aktivitas pada jalur pedestrian menyebabkan konflik pemanfaatan ruang (Pradipto, Kharis, Wicaksono, \& Indriastuti, 2014; Setyowati, 2011).

Sebagai tujuan wisata pedestrian seharusnya tidak mengurangi fungsi utamanya sebagai tempat pejalan kaki yang nyaman dan aman, juga harus memperhatikan kenyamanan wisatawan. Penelitian ini bertujuan ingin persepsi wisatawan keberadaan Wisata Pedestrain Sudirman.

\section{Metode}

$\begin{array}{llr} & \text { Metode } & \text { penelitian kualitatif } \\ \text { adalah metode } & \text { penelitian yang } \\ \text { berlandaskan } & \text { pada } & \text { filsafat } \\ \text { postpositivisme, digunakan untuk }\end{array}$
meneliti pada kondisi obyek yang alamiah, sebagai lawannya adalah eksperimen (Sugiyono, 2015). Dimana peneliti adalah sebagai instrumen pengambilan kunci, pengambilan sampel sumber data dilakukan secara purposive dan snowball. Analisis data bersifat induktif, dan hasil penelitian kualitatif lebih menekankan makna dari pada generalisasi

Data dan sumber data melalui wawancara atau pengamatan merupakan hasil gabungan dari kegiatan melihat, mendengar, dan bertanya. Data primer adalah data yang diperoleh pengukuran langsung di lapangan. Sumber data primer yang digunakan dalam penelitian ini meliputi:

(1) informasi dari masyarakat atau wisatawan yang berkunjung di Wisata Pedestrian Sudirman, (2) informasi dari Pengelola dari Wisata Pedestrian Sudirman dan (3) informasi dari PKL di sekitaran Jalan Pedestrian Sudirman/ Data sekunder dalam penelitian ini adalah hasil yang diperoleh bukan secara langsung dari sumbernya. Penelitian ini sumber data sekunder yang dipakai adalah tertulis seperti sumber buku, dan dokumen-dokumen dari pihak yang terkait dengan Wisata Pedestrian Sudirman.

Teknik pengumpulan data merupakan langkah yang paling utama dalam peneitian karena tujuan utama dari penelitian adalah mendapatkan data, tanpa mengetahui teknik pengumpulan data, maka peneliti tidak akan mendapatkan data yang memenuhi standar data yang ditetapkan pengambilan data ini di ambil menjadi tiga sebagai berikut. Pertama, dokumentasi. Sejumlah besar fakta dan data tersimpan dalam bahan yang berbentuk dokumentasi. Sebagian besar data yang tersedia adalah berbentuk surat-surat, catatan harian, laporan, dan lain sebagainya. Kedua, observasi. Observasi sebagai teknik 
pengumpulan data dengan cara mengamati secara langsung dilapangan. Ketiga, wawancara. Teknik pengumpulan data dengan wawancara adalah mewancarai secara langsung kepada responden baik pengunjung, $\mathrm{PKL}$, maupun petugas pengelola Wisata Pedestrian Sudirman.

\section{Hasil dan Pembahasan}

Wisata pedestrian sudirman adalah obyek wisata baru dikembangkan di Kota Palembang, sama seperti Yogyakarta memupnyai malioboro, kalau di Kota Palembang ada pedestrian sudirman. Inilah destinasi baru yang lagi ramai-ramai dikunjunmgi wisatawan selain untuk menghidupkan malam di sepanjang jalan protokol. Destinasi ini ditunjukan dulunya untuk seagames pada tahun 2018 dulu tetapi sekarang wisata ini masih di lanjutkan karena respon masyarkat cukuplah baik wisata malam di Kota Palembang tampaknya menawarkan segudang pemandangan bagi pengunjung yang ingin berlibur atau sekedar menikmati kuliner dengan melihat atraksi dari budaya lokal. Sebagai kota tertua yang kaya akan budaya. Kota Palembang menawarkan destinasi wisata baru pengunjungpun dapat mnghabiskan malam bersama keluarga, teman dekat ataupun tamu untuk berkumpul di sepanjang jalan protokol pedestrian sudirman dan juga banyak wisatawan lokal maupun wisatawan luar berkunjung disana.

Pedestrian Sudirman sebagai tempat wisata menjadi ajang bagi masyarakat pelaku seni untuk menunjukan kesenian lokal sesai dengan kearifal lokal masing-masing yang ada di seluruh kabupaten kota yang ada Provinsi Sumatera Selatan. Kegiatan ini akan menarik bagi wisatawan asing untuk datang dan memperkenalkan budaya-budaya yang ada.

Hasil penelitian ini diperoleh dari masyarakat sebagai sempel penelitian dengan berjumlah 10 orang dan cara pengumpulan data penelitian ini melalui wewancara dan dokumentasi guna mengetahui persepsi masyarakat mengenai wisata pedestrian sudirman dengan menggunakan 7 sapta pesona yaitu aman, tertib, bersih, sejuk, indah, ramah, kenangan.

Berdasarkan observasi penelitian bahwa keamanan adalah keadaan bebas dari bahaya. Istilah ini bisa digunakan dengan hubungan kepada kenyamanan bagi setiap orang dengan hubungan kejahatan serta segala bentuk kecelakaan infrastruktur dan lain-lain. Keterangan dari hasil penelitian yang ada di wisata pedestrian sudirman tersebut menyatakan bahwa sebagian besar responden menyatakan aman bila berada di wisata pedestrian sudirman. Hal ini sama dengan penelitian (Khalik, 2014) dalam penelitiannya menyatakan bahwa faktor yang mempengaruhi keamanan dan kenyamanan di suatu wisata yaitu faktor lingkungan, faktor ekonomi, dan faktor akses jalan pariwisata apabila tempat wisata sudah memiliki ke tiga faktor tersebut otomatis wisatawan akan merasa aman dan nyaman bila berada di wisata tersebut.

Tertib adalah keadaan yang sesuai dengan aturan sehingga berjalan tidak berantakan dan teratur (Waluyo, 2013). Ketertiban yang ada di wisata pedestrian sudirman bisa dibilang cukup tertib bagi beberapa 
responden mengatakan bahwa wisatawan yang datang di Wisata Pedestrian Sudirman terjaga dan kondusif tidak ada hal-hal yang merugikan bagi setiap pengunjung yang ada di sana sehingga memberikan kenyaman begi mereka ketika berkunjung.

Kebersihan sendiri bisa memberikan kenyamanan bagi setiap oranng, layanan destinasi yang mencerminkan keadaan bersih, sehat hingga memberi rasa nyaman bagi kunjungan wisatawan, berpikiran positif pangkal hidup bersih, tidak asal buang sampah/limbah, menjaga kebersihan Obyek Wisata, kebersihan yang ada di pedestrian sudirman bisa dikatakan cukuplah bersih bagi bebrapa responden yang mengatakan petugas kebersihan selalu membersihkan tempat wisata serta selalu tersedianya kotak sampah yang banyak di wisata pedestrian sudirman. (Buana \& Sunarta, 2015) wisata yang bersih dan bebas dari sampah tentu akan membersihkan kesan yang nyaman dan baik bagi wisatawan yang berkunjungke wisata pedestrian tersebut. Selain itu juga akan memberikan dampak yang posotif juga bagi kesehatan wisatawan dan sektor yang berperan di pariwsata pedestrian sudirman sehingga apabila bersih wisatawan akan sejuk melihatnya.

Kesejukan sendiri adalah sebuah destinasi wisata yang sejuk dan teduh akan memberikan perasaan nyaman dan betah bagi kunjungan wisatawan, seperti melihat pepohonan menanam pohon atau penghijauan memelihara penghijauan di tempat tinggal terutama pada jalur wisata, dari hal tersebut sehubungan dengan penelitian ini persepsi masyarakat menurut responden dikatogorikan cukuplah sejuk saat brada di sekitaran jalan pedestrian sudirman saat malam hari. (Savitri \& Sulistyowati, 2018) Menyatakan bahwa dalam hal kesejukan disuatu wisata agar wisatawan tetap nyaman seharusnya tempat wisata itu selalu tampak bersih dan indah seperti kerapian, tempat sampah memadai, kesejukan, dan keindahan.

Keindahan yang ada di jalur pedestrian tersebut cukuplah menarik bagi beberapa responden dengan melihat atraksi yang ada disana dengan paronama yang cocok untuk berjalan kaki di malam hari. Namun ada juga beberapa wisatawan yang mengatakan bosan dengan hal tersebut saran saya bagi sang peneliti seharusnya ateraksi yang ada disana haruslah ditambah lagi supaya wisatawan melihat hal baru disana dan tidak mudah merasa bosan.

\section{Penutup}

Persepsi wisatawan mengenai wisata pedestrian sudirman, dapat disimpulkan bahwa persepsi wisatawan mengenai wisata pedestrian sudirman cukuplah baik bagi beberapa responden yang ada namun ada juga sedikit dari responden mengatakan tidak begitu nyaman bila berada di wisata pedestrian sudirman dikarnakan masih kurang rapi dan bersih sehingga maka dari itu beberapa wisatawan kurang begitu nyaman bila berada di wisata tersebut. Perlu dukungan pemerintah dalam pengembangan Wisata Pedestrian Sudirman, terutama dari sisi ketertiban dan keamanan para pedestrian. Sehingga keamanan dan kenyamanan wisatawan tetap terjaga. 


\section{Daftar Pustaka}

Buana, D. W. W., \& Sunarta, I. N. (2015). Peranan sektor informal dalam menjaga kebersihan lingkungan di daya tarik wisata pantai sanur. Jurnal Destinasi Pariwisata, 3(1), 35-44.

Ditarani, F., \& Wibisono, B. H. (2020). Dampak Peningkatan Kualitas Fisik Terhadap Perekembangan Aktivitas Sosial-Ekonomi. Geodika1, 4(1), 55-64. https://doi.org/10.29408/geodika.v 4i1.1981

Khalik, W. (2014). Kajian kenyamanan dan keamanan wisatawan di kawasan pariwisata kuta lombok. Jurnal Master Pariwisata, 1(1), 113.

https://doi.org/10.24843/JUMPA.2 014.v01.i01.p02

Mauliani, L. (2010). Fungsi dan peran jalur pedestrian bagi pejalan kaki. Architectural Journal of NALARs, 9(2), 165-176. https://doi.org/10.24853/nalars.9.2. $\% 25 p$

Muslihun, M. (2013). Studi Kenyamanan Pejalan Kaki Terhadap Pemanfaatan Jalur Pedestrian Di Jalan Protokol Kota Semarang (Studi Kasus Jalan Pahlawan). Universitas Negeri Semarang.

Oswan, D. B., \& Sigit, A. L. (2013). Fungsi Pedestrian Jalan Tunjungan Dari Sirkulasi Ke Rekreasi: Studi Kasus Berdasarkan Kesejarahan. Journal of Architecture and Built Environment, 40(2), 99-111. https://doi.org/10.9744/dimensi.40. 1.99-112
Pradipto, R., Kharis, Z., Wicaksono, Y. I., \& Indriastuti, A. K. (2014). Evaluasi Kinerja Ruang Pejalan Kaki Di Jalan Malioboro Yogyakarta. Jurnal Karya Teknik Sipil, 3(3), 564-572.

Pratitis, A. (2015). Kajian Perkembangan Aktivitas Sosial dan Rekreasi di Jalur Pedestrian (Studi Kasus: Jalur Pedestrian Jalan Pahlawan). Jurnal Pembangunan Wilayah Dan Kota, 11(2), 129-141. https://doi.org/10.14710/pwk.v11i2. 10843

Savitri, S. N., \& Sulistyowati. (2018). Upaya Pemerintah Dalam Menjalankan Sapta Pesona Pariwisata Di Kabupaten Magetan. Journal of Politic and Government Studies, 8(1), 1-13.

Setyowati, M. D. (2011). Pemanfaatan Pedestrian Ways di Koridor Komersial di Koridor Jalan Pemuda Kota Magelang. Jurnal RUAS, 15(1), 13-22. https://doi.org/10.21776/ub.ruas.20 17.015.01.2

Sugiyono. (2015). Metode Penelitian pendidikan Pendekatan Kuantitatif, Kuantitatif dan R\&D. Bandung: Alfabeta.

Waluyo, J. E. (2013). Implementasi sapta pesona pada usaha pariwisata di Kota bandung. Bandung. 